Resultate erhalten. Verfasser versuchte deshalb den Nachweis in der Weise zu führen, dass er die Farbstoffe «Orange I» ( $\alpha$-Naphtolverbindung) und «Orange $\mathrm{II} \gg$ ( $\beta$-Naphtolverbindung) durch Einwirkung der betreffenden Naphtole auf azotirte Sulfanilsäure darstellte, da diese Farbstoffe recht charakteristische Unterschiede zeigen.

Man löst 5 Centigramm Sulfanilsäure in $5 c c$ Normalnatronlauge, fügt $5 \mathrm{cc}$ Normalschwefelsäure hinzu und mischt die Lösung mit $2 \mathrm{cg}$ Natriumnitrit, die in wenigen Tropfen Wasser gelöst sind.

$\mathrm{Zu}$ einer Lösung von $4 \mathrm{cg}$ Naphtol in $0,5 c c$ Normalnatronlauge bringt man alsdann die obige azotirte Sulfanilsäurelösung. War $\alpha$-Naphtol angewandt, so wird die Lösung dunkel blutroth, dagegen bei $\beta$-Naphtol röthlichgelb gefärbt. Der Farbenunterschied ist noch schärfer, wenn man die Farbstoffe aussalzt. Der $\alpha$-Naphtolfarbstoff (Orange I) wird mit verdünnter Schwefelsäure dunkelbraun, während die $\beta$-Naphtolverbindung (Orange II) unverändert bleibt. Dieser letztere Unterschied ist sehr charakteristisch.

\title{
Ueber den Gerbstoff des Holzes der Edelkastanie (Castanea vesca)
} hat Henry Trimble ${ }^{1}$ ) Stadien gemacht. Er weist am Anfang seiner Mittheilungen darauf hin, dass man sich bei Angaben über Kastaniengerbsäure vor Verwechslungen zu hüten habe, da einerseits die meisten Litteraturangaben sich auf das Tannin der Rosskastanie (Aesculus Hippocastanum) beziehen und andererseits ausser dem eigentlichen Kastanienholzextract auch noch ein solches von der Chesnut oak (Quercus Prinus L.) in den Handel komme und in der Bezeichnung oft nicht genügend von ersterem unterschieden werde ${ }^{2}$ ).

Zur Herstellung des Gerbstoffs zog der Verfasser fein gemahlenes Holz mit käuflichem, alkoholhaltigem Aether aus, colirte, destillirte den Aether ab, nahm den Rückstand mit Wasser auf, filtrirte und fällte die Lösung mit Blejessig, und zwar in drei Fractionen. Die Niederschläge wurden mit Schwefelwasserstofi zersetzt, letzterer durch Eindampfen bei vermindertem Druck entfernt und die Lösungen sodann nach dem Abkühlen mit Aether behandelt, welcher bei allen drei Fractionen Gallussäure löste.

1) Chem. News 64, 251.

2) Die ausführliche Abhandlung über den Gerbstoff der Castanea vesca von P. Nass (vergl. diese Zeitschrift 25, 134) scheint dem Verfasser nicht bekannt gewesen zu sein. 
Die der mittleren Bleifällung entsprechende Gerbstofflösung wurde zur Entfernung des Aethers erwärmt und dann mit Kochsalz gesättigt. Hierdurch. wurde eine starke Ausscheidung von Gerbstoff bewirkt; diese wurde mit gesättigter Kochsalzlösung ausgewaschen und über Schwefelsäure im Vacuum getrocknet. Hierauf wurde der Gerbstoff in AetherAlkohol gelöst und durch rasche Verdunstung der Lösung unter vermindertem Druck in Form einer porösen, schwach röthlichen Masse erhalten. Für die meisten der im Original angefühten Reactionen wurde das Reinigungsverfahren durch fractionirte Fällung mit Bleiessig und Behandlung der dann erhaltenen wässerigen Lösung mit Aether zur Entfernung der Gallussänre nochmals wiederholt, worauf ein fast weisses, im äusseren Ansehen und im Verhalten mit dem gewöhnlichen Tannin so völlig übereinstimmendes Product erhalten wurde, dass der Verfasser beide für identisch hält.

2. Quantitative Bestimmung organischer Körper. a. Elementaranalyse.

Ueber die Bestimmung des Stickstoffs in organischen Substanzen hat Lyman F. Kebler ${ }^{1}$ ) eine Abhandlung veröffentlicht, welche eine sehr ausführliche Zusammenstellung der gesammten Litteratur über diesen Gegenstand enthält ${ }^{2}$ ). Ausserdem gibt der Verfasser noch die Resultate seiner Versuche über die Anwendbarkeit der Kjeldahl'schen Methode, insbesondere bei Gegenwart von Nitraten an. Er verfuhr bei seinen Analysen nach den Vorschriften von $\mathrm{Scovel}^{3}$ ) und fasst seine Resultate in folgenden Sätzen zusammen:

1) Die Kjeldahl'sche Methode liefert bei der Bestimmung des Nitratstickstoffs nicht ganz so genaue Werthe wie die absolute Methode (nach Dumas), aber sie erfordert viel weniger Zeit, da gleichzeitig mehrere Bestimmungen ausgeführt werden können. Für alle praktischen Fälle ist die Methode durchaus anwendbar.

2) Es ist nöthig die Schwefelsäure rasch zuzusetzen, damit kein Verlust durch Entweichen von Salpetersäure entsteht.

1) Journal of analytical and applied chemistry 5, 257, vom Verfasser eingesandt. handen.

2) Leider sind in derselben bei den Autorennamen seh: viele Fehler vor-

3) Vergl. diese Zeitsehrift 28, 625, sowie ferner Bull. of the U. S. Agr. Dep. No. 19, 43 und No. 24, 85. 